\title{
Speciation of the tintinnid genus Cymatocylis by morphometric analysis of the loricae
}

\author{
R. Williams ${ }^{1}$, H. McCall ${ }^{1}$, R. W. Pierce ${ }^{2}$, J. T. Turner ${ }^{3}$ \\ 'Plymouth Marine Laboratory, Prospect Place, The Hoe, Plymouth PL1 3DH, United Kingdom \\ ${ }^{2}$ Graduate School of Oceanography, University of Rhode Island, Narragansett, Rhode Island 02882, USA \\ ${ }^{3}$ Biology Department and Center for Marine Science and Technology, University of Massachusetts, Dartmouth, \\ Massachusetts 02747, USA
}

\begin{abstract}
Samples of the tintinnid genus Cymatocylis were collected at an oceanic site near South Georgia in January 1990. The shapes and sizes of loricae observed included most forms previously reported by other authors and were representative of the entire genus. Measurements were taken from the loricae of over 700 specimens and 201 photomicrographs were obtained, from which further detailed measurements were taken. Univariate frequency histograms and bivariate scatter plots of the morphometric measurements were compared with multivariate techniques including: hierarchical nearest neighbour cluster analysis, linear discruminant analysis and canonical analysis with resubstitution on the model to $95 \%$ confidence intervals. Fourier transforms of digitised images of the photomicrographs were utilised as functions of the overall shape of the organisms, and input to both the linear discriminant function and canonical function with resubstitution on the model to $99 \%$ confidence intervals for comparison with results obtained from the manual morphometric measurements. Linear discriminant analysis showed 5 clear taxonomic classes corresponding to the original descriptions of $C$. calyciformis, C. convallaria, C. vanhöfeni, C. parva and C. drygalskii. Resubstitution onto the canonical models gave correct classification for the manual morphometric data and $100 \%$ correct classification for the Fourier transform data. These results showed that a clearer discrimination was obtained by utilising a multivariate 'description' of the overall shape. The cluster analysis showed that absolute size was not necessary for the identification. The univariate and bivariate approaches demonstrated some discernible separation, but with considerable overlap between species, especially C. vanhöffeni and C. drygalskii. These statistical methods were used to demonstrate that clear discrimination can be obtained from morphometric data and should allow for the development of automated taxonomic classification.
\end{abstract}

KEY WORDS: Antarctic · Tintinnids · Taxonomy

\section{INTRODUCTION}

The plankton food web of the Antarctic Ocean is traditionally thought of as consisting of diatoms, krill and whales, but recent discoveries suggest that the microbial component may play an important role, as in other ecosystems (reviewed in Garrison 1991). One of the most conspicuous components of the protozooplankton in the Southern Ocean is the tintinnids.

The tintinnid genus Cymatocylis is endemic to the Antarctic Ocean (Pierce \& Turner 1993) and is often the dominant genus present (Boltovskoy et al. 1989, Wasik \& Mikolajczyk 1990, Alder \& Boltovskoy 1991). Despite this, and the fact that this genus has been known since 1907 (Laackmann 1907), identification at the species level remains problematic. The main source of taxonomic confusion in the tintinnids stems from the natural phenotypic variability expressed in the loricae, and the failure of most taxonomic works to address this variability in the species descriptions. Thus there have been several papers calling for abandonment of lorica morphology as the basis of species identification, or at least for the inclusion of cytological characteristics in considering species identification (Davis 1978, 1981, Bakker \& Phaff 1979, Laval-Peuto 1981, 1983, Laval-Peuto \& Brownlee 1986). While cytological characteristics are extremely valuable, especially in determining taxonomic relationships and in original descriptions of species, it is simply not practical to abandon the lorica as the primary means of identification, especially in ecological 
studies. Thus it is very important that the variation of lorica morphology be studied and guidelines be established for accurately speciating tintinnids by their morphological characteristics. In this study, morphometric measurements of the loricae of the genus Cymatocylis are taken and a comparison made between the traditional univariate and certain multivariate approaches to the problem of classification. It is hoped that the adoption of a multivariate approach to morphometric classification will avoid the limitations of broad overlapping ranges of univariate measurements and bivariate relationships. The results from this approach to classification lead into the description of an automated approach to multivariate classification by artificial neural networks given in the accompanying paper (Culverhouse et al. 1994, this volume).

\section{MÄTERIALS AND METHODS}

Tintinnids were collected from several stations near South Georgia in January 1990 using the Longhurst Hardy Plankton Recorder (Williams et al. 1983, Atkinson et al. 1992) and preserved in $10 \%$ buffered formalin. Near surface samples were used because they contained the greatest abundance of Cymatocylis. The Cymatocylis specimens were measured using 2 techniques: (1) all specimens were measured directly from the microscope using an image analysis system linked to an Olympus BH2 compound microscope with phase contrast, and (2) a subset of these specimens were measured from photomicrographs. These were obtained using a $35 \mathrm{~mm}$ camera fitted to the compound microscope, the photomicrographs having a final magnification of $\times 240$. The photomicrographs were digitised using a Panasonic wv-cd50 camera to provide grey-level images for input to the neural network described by Culverhouse et al. (1994). Fourier transforms (Gonzalez \& Woods 1992) were computed from contrast enhanced copies of these $256 \times 256$ pixel grey-level images.

Microscope measurements. Measurements were taken from 718 specimens of the genus Cymatocylis. Only relatively undamaged loricae, laying relatively flat, were measured. Total length, bowl length and internal lorica oral diameter were measured. The bowl length, on the image analysis system, was measured from a line actually drawn across the long axis of the oral diameter elipse to another line drawn at an arbitrary point where it was judged that the lorica would end if it did not have a pedicel. The pedicel length was not measured but calculated from total length minus bowl length.

Photomicrograph measurements. A subset of 201 photomicrographs of Cymatocylis were measured using vernier calipers. Measurements taken were total lorica length, bowl length and lorica oral diameter, with pedicel length again being derived from the difference between bowl and total length. An additional measurement, depth of oral opening equating to the maximum depth of the oral elipse, was taken to correct for rotation in the perpendicular plane. The loricae were assumed to be cylindrical for the purpose of this correction. The point at which the bowl met the pedicel was taken to be the lowest point of the lorica bowl's internal cavity so as to provide a more objective locus for measurements.

Morphometric analysis. Univariate histograms were prepared from the 718 microscope specimens and bivariate scatter plots were prepared for both data sets for comparison. Three multivariate techniques were applied to the photomicrograph data. A hierarchical nearest neighbour cluster analysis (Clarke 1993) was used as an unsupervised procedure to establish any natural tendency for the specimens to cluster on the parameters measured. Initially no scale bars were included for the photomicrographs and arbitrary units were used for the measurements; the similarity table was derived from a correlation matrix to remove absolute size from the equation. The analysis was performed with software developed at Plymouth Marine Laboratory. Two discriminant functions were applied to the photomicrograph data (Phillips et al. 1973) using the statistical package SAS (SAS Institute 1985). A linear parametric discriminant function was utilized to compute the Mahalanobis distances, assuming a normal distribution. The Mahalanobis is the generalized squared distance between the means of groups derived from the within-group covariances. This makes allowance for the possibility of features overlapping between species such that an aberrant specimen from one species might be closer to the bounds of another species rather than its own. In this case the specimen is still likely to be closer to its own species mean as derived from the within-group covariance than to the mean of the other species. This is only possible because this is a supervised procedure requiring prior knowledge of the assumed class. A canonical discriminant function was applied to test each specimen for probability of inclusion in each class (species). This function folds the multidimensional data into 2 canonical variables providing, at each fold, the maximum separation between all loci. Confidence intervals of $95 \%$ were set on the probabilities and plots of the first 2 canonical variables for each specimen, in both the photomicrograph and microscope data, were produced. The Fourier transforms from the contrast enhanced grey-level images were sampled to give 127 interpolated means for the 128 frequencies represented. The 127 interpolated means were used as input to the discriminant functions to compare with the manually measured parameters 


\section{RESULTS}

\section{Univariate analysis}

Five different forms of Cymatocylis were observed in the data corresponding to $C$. calyciformis, C. convallaria, C. vanhöffeni, C. parva and C. drygalskii. The spe- cies, with examples of their range of morphological variability, are shown in Fig. 1. Total lorica length ranged from 48 to $444 \mu \mathrm{m}$ and oral diameters ranged from 39 to $113 \mu \mathrm{m}$. A frequency histogram of lorica oral diameter clearly demonstrates at least 2 species present with mean oral diameters of 46 and $92 \mu \mathrm{m}$, Fig. 2. The lower size range comprised all the $C$. parva with the remain-

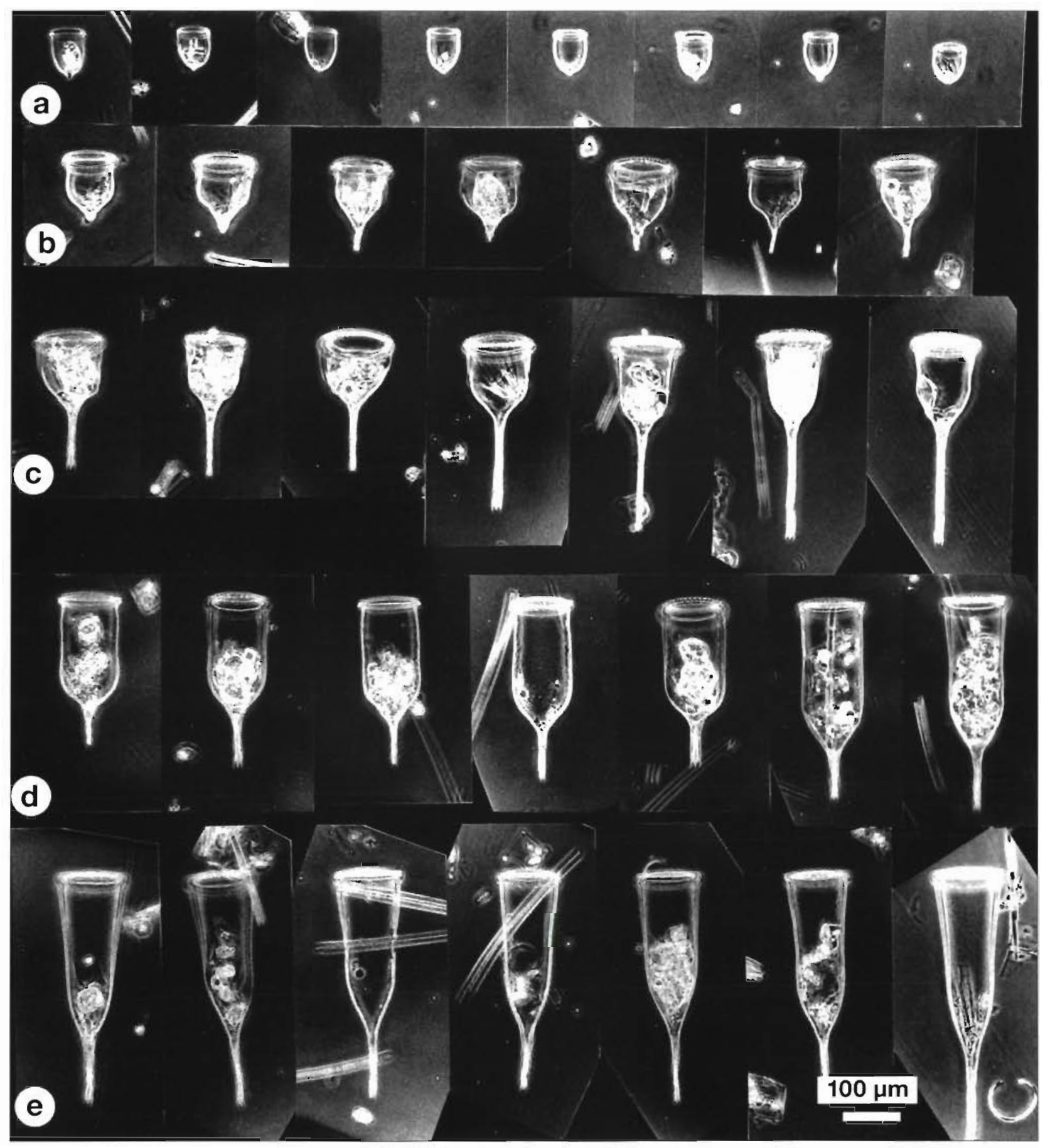

Fig. 1. Cymatocylis spp. (a) C. parva, (b) C. convallaria. (c) C. calyciformis, (d) C. drygalskii, (e) C. vanhoffeni, showing the range of morphological variability 

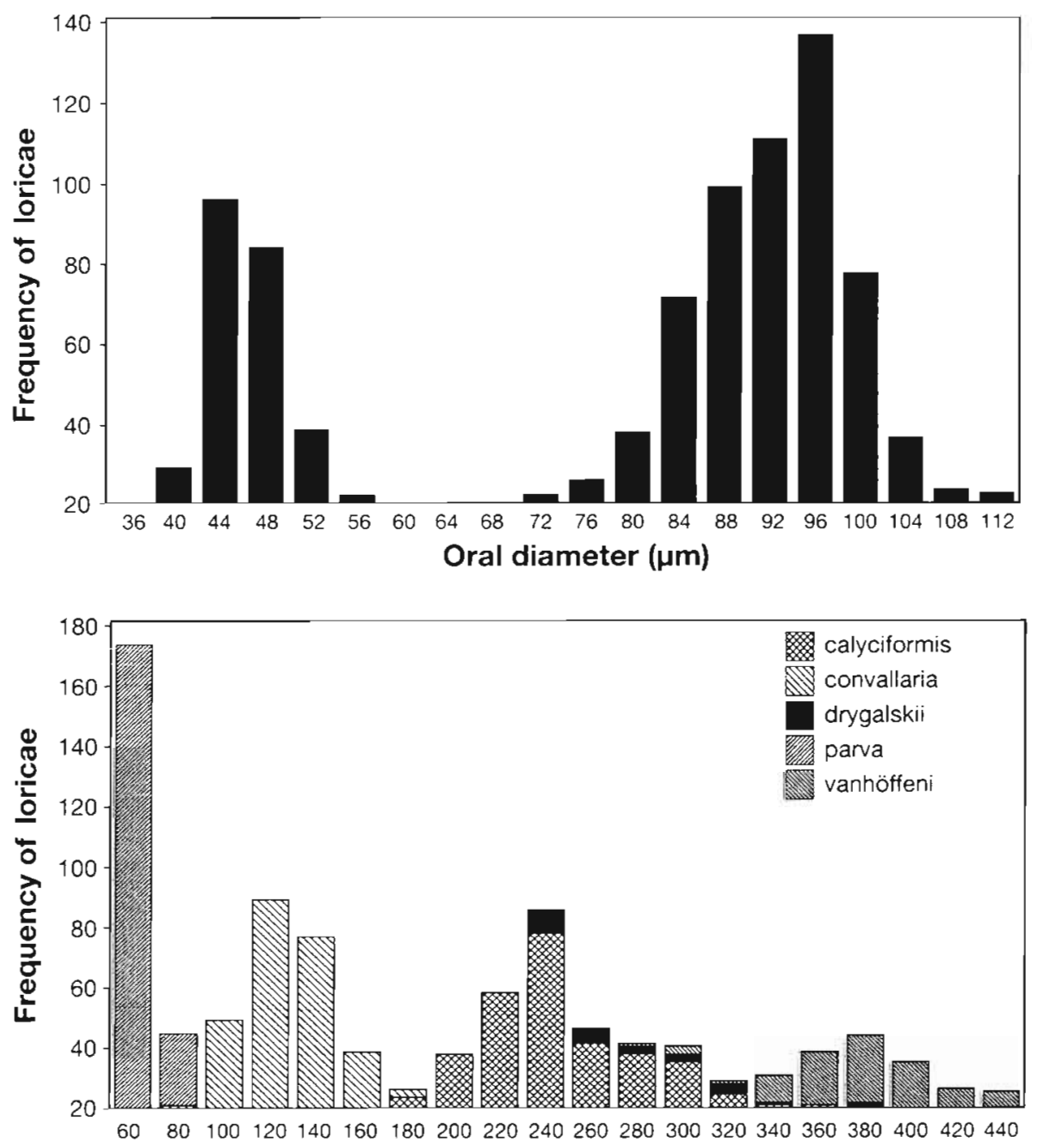

Fig. 2. Cymatocylis spp. Frequency histogram of lorica oral diameter

Total lorica length $(\mu \mathrm{m})$

ing species in the upper size range. A frequency histogram of total lorica length (Fig. 3) shows 4 normally distributed groupings with $C$. drygalskii overlapping between $C$. calyciformis and $C$. vanhöffeni.

The scatter plots of bowl length against total length (Fig. 4a) show a good separation for all 5 species on the photomicrograph data which were corrected for perpendicular orientation; only $C$. drygalskii and C. vanhöffeni overlap to any degree. This plot also clearly shows 2 horizontal broad bands corresponding to the short-bowled group of $C$. calyciformis, $C$. convallaria and $C$. parva and the long-bowled group of $C$. vanhöffeni and C. drygalskii. However, it also shows that there is a continuous sequence of overlapping ranges of bowl lengths across the genus with only a small reduction in frequency at the meeting of $C$. calyciformis and $C$. drygalskii, which may be an artifact of sampling. The scatter plot for the microscope data given in Fig. 4 b shows more overlap between species though there is a sharper division between long- and short-bowled species.

\section{Multivariate analysis}

The cluster analysis (Fig. 5) shows the 201 specimens clustering at a $95 \%$ similarity into 5 single-species clusters and 2 two-species complex clusters. This analysis utilises a correlation matrix, therefore, the absolute values of the measurements are standardised out leaving the results dependent on the relative proportions of the morphological features. Cymatocylis vanhöffeni, C. parva and C. calyciformis each clustered to single loci suggesting a low variability in their relative proportions, the aberrant $C$. calyciformis having an abnormally long pedicel. The $C$. drygalskii clustered with the $C$. vanhöffeni. These 2 species have very similar proportions and sizes with the main distin- 
Fig. 4. Cymatocylis spp. Scatter plots of bowl length against total length of lorica tor data measured from (a) photomicrographs and (b) microscope
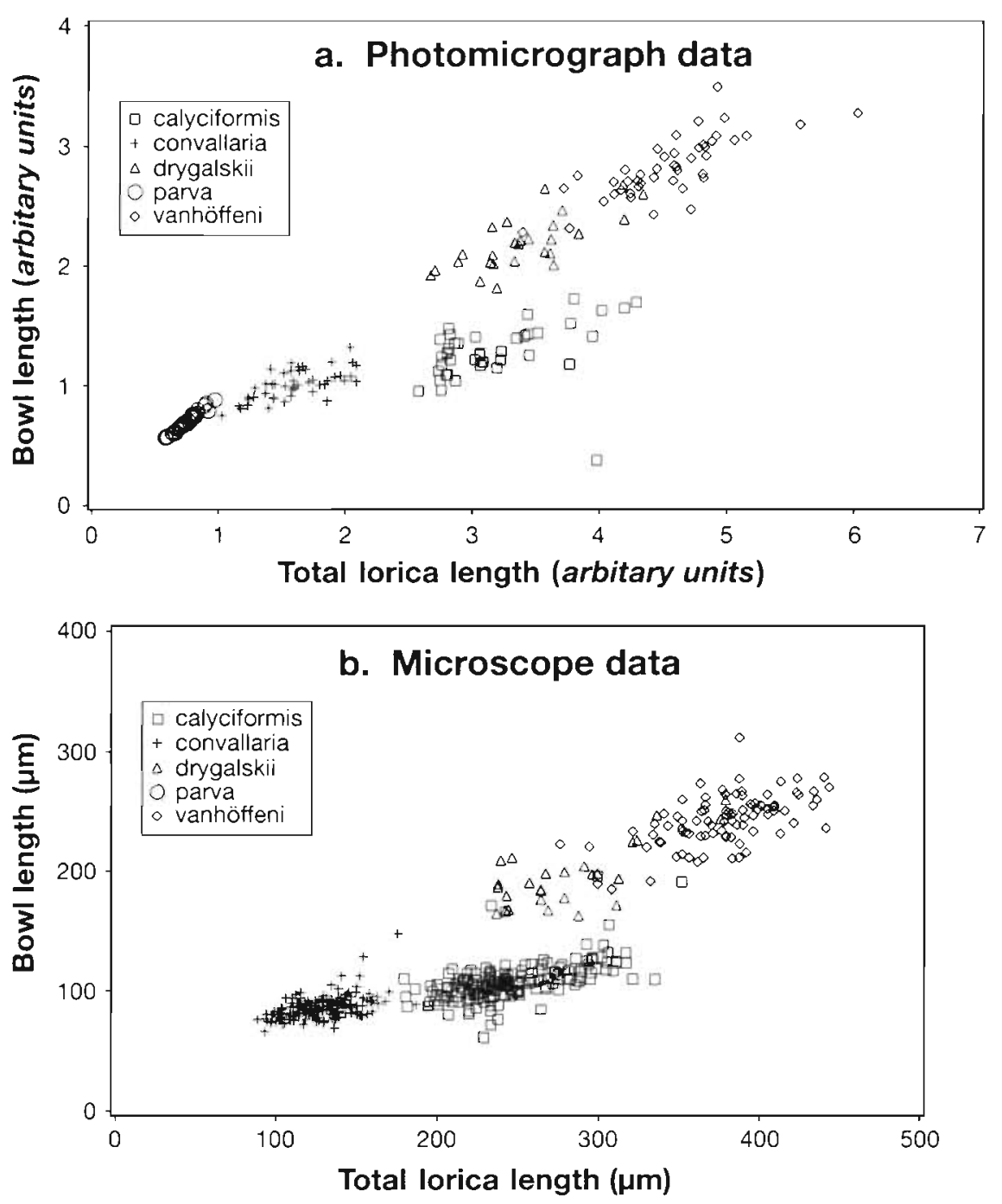

quishing feature being the long fluting of the bowl into the pedicel of C. vanhöfeni. Seven of the C. drygalskii

\section{Percentage similarity}

$\begin{array}{lllllllllll}0 & 10 & 20 & 30 & 40 & 50 & 60 & 70 & 80 & 90 & 100\end{array}$

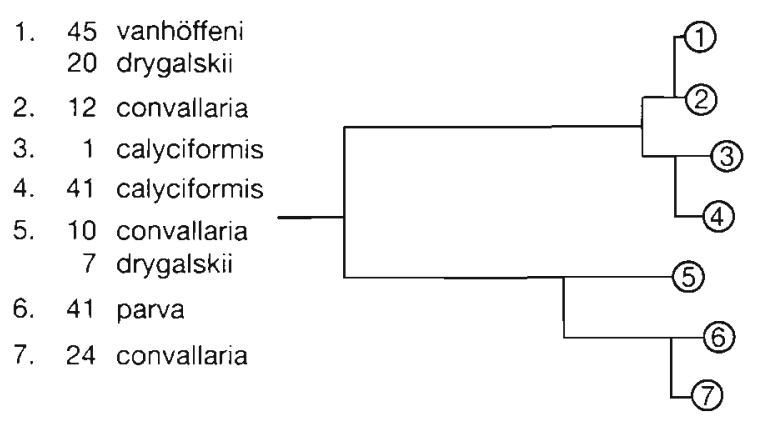

Fig. 5. Dendrogram of percentage similarity of Cymatocylis species using data measured from the photomicrographs clustered with 1 of the 3 groups of C. convallaria, although this is an artifact because of the removal of absolute size. The $C$. convallaria were divided into 3 clusters, interspersed amongst the other species. This shows for $C$. convallaria that despite the absolute size range being narrow and isolated from the other species (Figs. $3 \& 4$ ) there is still a large variability in the relative proportions of the features of this species.

The Mahalanobis distances from the discriminant analysis (Table 1) show a minimum of 16.6 between Cymatocylis drygalskii and C. vanhöffeni. Since these distances are a function of a square, they give greater resolution for the shorter distances. The canonical plot for the photomicrograph data (Fig. 6a) shows a 2dimensional projection of the individual specimen distances on resubstitution into the model and clearly follows the same trend as the Mahalanobis distances for the overall classes, with $C$. vanhöffeni and $C$. parva being at maximum separation. In contrast, $C$. vanhöffeni and C. drygalski are at minimum separation and 

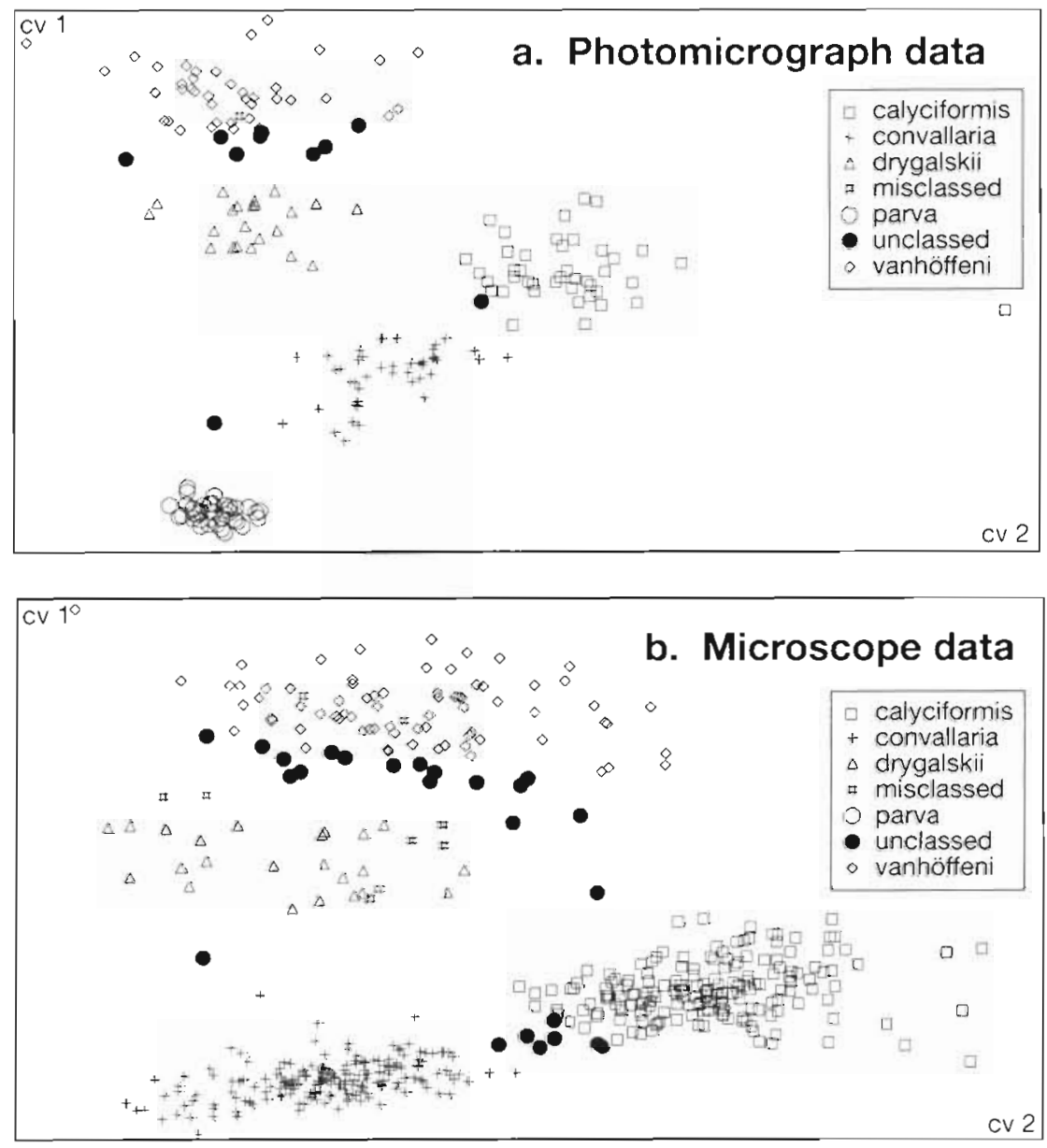

Fig. 6. Canonical plots of morphometrics together with $95 \%$ confidence intervals of Cymatocylis spp. taken from (a) photomicrograph and (b) microscope. CV: canonical variable

form an overlapping band of unclassed individuals at the $95 \%$ confidence limits. The square function of the distances is not very apparent on the canonical plots due to the orientation in multidimensional space necessary to project onto 2 dimensions. The individual $C$. calyciformis, at the right edge of Fig. $6 \mathrm{a}$, was the same individual which clustered alone in Fig. 5 and had an abnormally long pedicel.

The resubstitution of the 201 photomicrograph specimens into the model (Table 2) shows that only 3 specimens were so far outside their species' normal bounds as to be misclassified. Only 1 of these individuals was reclassified to $95 \%$ confidence. Two of them were specimens of Cymatocylis drygalskii on the boundary with $C$. vanhoffeni, and the third was a C. convallaria with virtually no pedicel. This specimen was similar to the leftmost specimen in Fig. 1, which was reclassed as C. parva but at a low probability. With the exception of 2 C. convallaria at the extreme limits of the species range the few specimens remaining outside the $95 \%$ confidence limits ('unclassed', Fig. 6a) all lay on the narrow boundary between $C$. vanhöffeni and $C$. drygalskii.

The discriminant analysis of the Fourier transform data shows a canonical plot (Fig. 7) very similar to that from the measured parameters (Fig, 6), the principle

Table 1. Mahalonobis distances between Cymatolcylis spp

\begin{tabular}{lccccc|}
\hline Class & C. calyciformis & C. convallaria & C. drygalskii & C. parva & C. vanhöffeni \\
\hline C. calyciformis & 0 & 25.886 & 31.406 & 105.046 & 68.236 \\
C. convallaria & & 0 & 41.729 & 35.818 & 108.307 \\
C. drygalskil & & 0 & 119.985 & 16.577 \\
C. parva & & & 0 & 224.328 \\
C. vanhöfeni & & & & 0 \\
\hline
\end{tabular}


Table 2. Cymatolcylis spp. Resubstitution on the model using data from the photomicrograph specimens

\begin{tabular}{|c|c|c|c|c|c|c|c|}
\hline & Class & C. calyciformis & C. convallaria & $\begin{array}{l}\text { Re-classed } \\
\text { C. drygalskij }\end{array}$ & C. parva & C. vanhoffeni & Total \\
\hline \multirow{5}{*}{$\begin{array}{l}\bar{\Xi} \\
\stackrel{\sigma}{\Xi} \\
0\end{array}$} & C. calyciformis & 42 & 0 & 0 & 0 & 0 & 42 \\
\hline & C. convallaria & 0 & 45 & 0 & 1 & 0 & 46 \\
\hline & C. drygalskii & 0 & 0 & 25 & 0 & 2 & 27 \\
\hline & C. parva & 0 & 0 & 0 & 41 & 0 & 41 \\
\hline & C. vanhöffeni & 0 & 0 & 0 & 0 & 45 & 45 \\
\hline \multicolumn{2}{|c|}{ Total } & 42 & 45 & 25 & 42 & 47 & 201 \\
\hline \multicolumn{2}{|c|}{ Error rates } & 0.0000 & 0.0217 & 0.0741 & 0.0000 & 0.0000 & 0.0192 \\
\hline
\end{tabular}

Table 3. Mahalonobis distances for Cymatolcylis transforms

\begin{tabular}{lccccc|}
\hline Class & C. calyciformis & C. convallaria & C. drygalskii & C. parva & C. vanhöffeni \\
\hline C. calyciformis & 0 & 101.425 & 97.576 & 184.989 & 301.807 \\
C. convallaria & & 0 & 186.114 & 87.435 & 448.698 \\
C. drygalskii & & 0 & 303.324 & 260.499 \\
C. parva & & & 0 & 565.389 \\
C. vanhöffeni & & & & 0 \\
\hline
\end{tabular}

difference being the lateral shift of Cymatocylis drygalskii to the right. The Mahalanobis distances for the classes derived from the Fourier transforms (Table 3) are an order higher than those obtained with manually measured parameters. A resubstitution on the canonical model gave correct classification to all specimens within $99 \%$ confidence limits.

\section{DISCUSSION}

It can be seen from the results that the classical approach to morphometric taxonomy, utilising univariate parameters, provides a high degree of overlap between the species. The oral diameter of the lorica is thought to be fairly invariate within species of the genus Cymatocylis (Laval-Peuto 1982, Boltovskoy et al. 1990). Although this measurement is considered by many to be the most conservative and practical of lorica morphometric characteristics (Gold \& Morales 1975, 1976, Laval-Peuto 1981, Laval-Peuto \& Brownlee 1986) it can be seen (Fig. 2) to divide the genus into only 2 normally distributed populations. These distributions correspond to C. parva in one and the remainder of the species in the other. The histogram of frequency to total length (Fig. 3) demonstrates clearly the degree of overlap between the species. Certainly these univariate parameters are insufficient to discriminate

Fig. 7. Cymatocylis spp. Canonical plots of

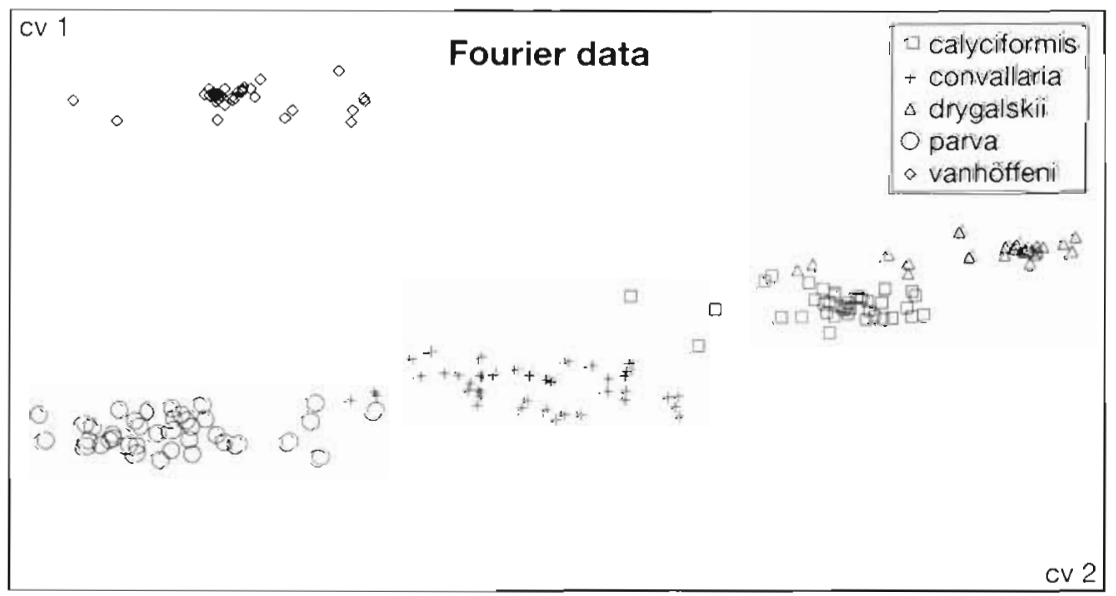

Fourier transforms of photomicrographs 
between species of Cymatocylis. In previous studies of Cymatocylis (Boltovskoy et al. 1990) and Favella (Laval-Peuto 1981), total length and oral diameter show unimodal and relatively normal-appearing distributions.

The bivariate plots (Fig. 4a, b) show good separation using bowl and pedicel length for the 5 species from the photomicrograph data, with significant overlap only between Cymatocylis vanhöffeni and C. drygalskii. The same plot performed for the much larger sample population from the microscope data shows a corresponding increase in overlap due to the greater range of variability sampled. For the large sample the distances shorten dramatically between $C$. calyciformis and C. convallaria and between C. calyciformis and $C$. drygalskii. Therefore, a larger sample population does not improve separation into the respective species. One reason bowl length may be more constant in Cymatocylis than in other genera is that no specimens were observed with any modifications to the original lorica such as extra collars. Such extra collars have been observed in several genera such as Favella, Helicostomella and Tintinnopsis (Gold \& Morales 1976 , Laval-Peuto \& Brownlee 1986). Similar to other genera, Cymatocylis does appear to form a coxlielliform replacement lorica. While rare in the samples, a few specimens were observed with such loricae (Fig. 8). These loricae match the dimensions of $C$. parva, and the short-bowled Cymatocylis.

Previously assigned to the genus Coxliella, such specimens have been reported before from Antarctic

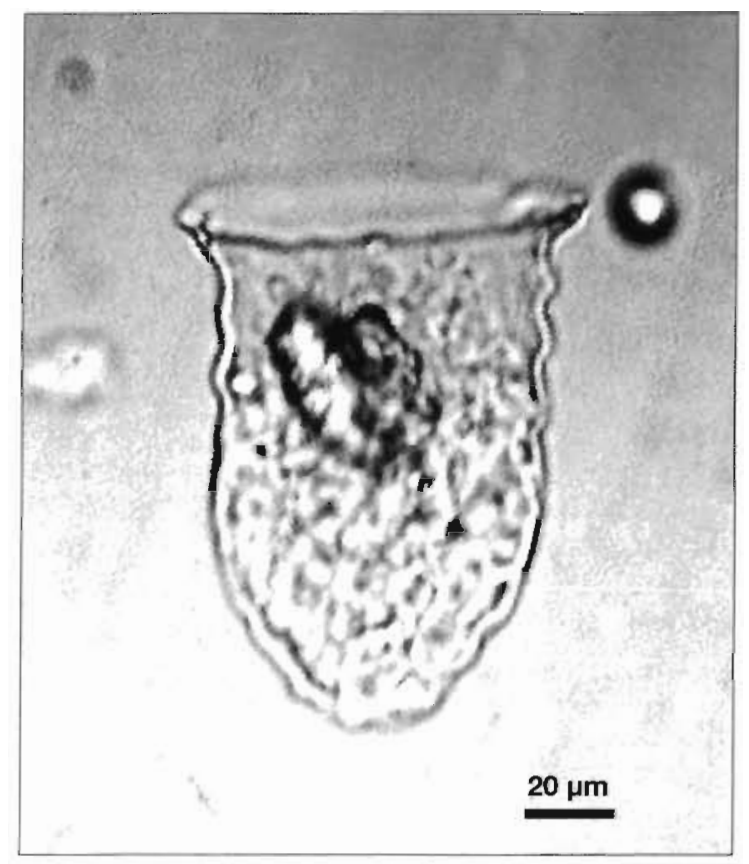

Fig. 8. Coxlielliform replacement Iorica of Cymatocylis sp. samples (Laackmann 1907, Balech 1958a, b, 1973, Sassi \& Melo 1986), but until now, have not been associated with the genus Cymatocylis. Coxlielliform loricae have been previously reported in the genera Favella, Parafavella, Helicostomella and Tintinnopsis (Laval-Peuto \& Brownlee 1986). Although the reliability of highly variable features, such as total length and especially pedicel length, may be controversial, there are no alternative explanations for the size distributions observed. Previous studies of a single species have not shown multimodal distributions of these characters. There are no life cycle events known which would explain these distributions either. Sexual dimorphism and alternation of generations are unknown in the tintinnids and coxlielliform replacement loricae approximate the same dimensions as the normal loricae. Therefore it is reasonable to assume that these 5 classes represent discrete species.

Although these uni-and bivariate plots demonstrate the presence of different 'species' in the data, it is only the results from the multivariate analyses which provide the direct methods for grouping these individuals into separate classes or species. In the multivariate plots (Fig. 6) the inter-class distances are derived from within-class covariance. Therefore, the broader range of parameters from the larger sample population simply fine-tune the overall class means such that the inter-class distances between $C y$ matocylis calyciformis and $C$. convallaria and between $C$. calyciformis and $C$. drygalskii remain reasonably constant for the larger sample. This means that the discrimination is not degraded by a broader range of specimens. The separation between $C$. drygalskii and $C$. vanhöfeni is poor throughout the univariate, bivariate and multivariate techniques. The principal cause for this is that their respective ranges for the measured parameters overlap to a considerable degree. From Fig. 1 it can be seen that the most easily identifiable discriminating feature between these 2 species is the angle at which the bowl meets the pedicel, the specimens of $C$. vanhöffeniconsistently having a more obtuse angle resulting in the long fluting of the lorica. Some of the increased overlap between these 2 species found in the canonical plots, for the microscope data, could be due to inaccuracies in the measurements. The $C$. drygalskii specimens measured with the microscope were the same set as for the photomicrographs, due to the low numbers of this species in the data set. Within the $95 \%$ confidence intervals only one of these $C$. drygalskii was misclassed from the photomicrograph data but several were misclassed with the microscope data. This was probably due to the more arbitrary locus chosen to represent the junction of the bowl and pedicel. This would be difficult to determine for $C$. vanhoffeni with its long fluted transition between bowl and pedicel; although 
accuracy could also be influenced by the lack of correction for perpendicular orientation in the microscope data. The difficulty in separating these species can be overcome by using Fourier transform data.

The Fourier transform is a mathematical analogue of a diffraction pattern obtained from the interference patterns generated by an object impinging on the transmission path from a coherent light source. It is therefore a function of the shape of the object. The close concurrence between the canonical plots for the photomicrograph measurement data (Fig. 6) and the Fourier transform data (Fig. 7) clearly demonstrates the value of the Fourier transforms as a mathematical function of the entire shape of the organisms. The use of the Fourier transform data in the discriminant analysis provides a clearer separation. The major differences between the 2 canonical plots are that Cymatocylis drygalskii is shifted to the right in the plot and $C$. vanhöffeni forms a much tighter distribution. The only easily observable discriminatory feature which was not measured was the angle at which the bowl joins the pedicel. Therefore, it may be reasonable to assume that the improved separation of the 2 species obtained with the Fourier data is due to the inclusion of that feature in the overall function of the shape.

We have illustrated a steady improvement of the discrimination achieved by the different methods, from a simple univariate statistic to increasing degrees of multivariate relationships. It can be appreciated that any morphometric classification which uses a function of overall shape of an organism will be more useful than any using individual morphometrics. A taxonomist identifying plankton will recognise the pattern of the overall shape of organisms, only resorting to morphometrics when there is uncertainty in the identifcation. It is hoped that we can assist the taxonomist in this labourious task of classification by automating this process by taking a video image from the microscope and feeding the overall function in the form of a Fourier transform into an artificial neural network. The excercise in this paper is intended to demonstrate that discrimination is feasible, even in this very difficult congeneric protozoan group, and that this approach can provide the basis for the development of an artificial neural network discriminator (Culverhouse et al. 1994).

Acknowledgements. We thank the captain and crew of RRS 'John Biscoe' and our colleagues in British Antarctic Survey for allowing one of us (R.W.) to join cruise No. 10 to South Georgia in 1989/1990. We thank Martin Carr for his guidance on the statistical analysis. This work formed part of the Laboratory Project 3 of the Plymouth Marine Laboratory of the U.K. Natural Environment Research Council. This work was partly funded by MAST 2 project number MAS2-92-0015c.

\section{LITERATURE CITED}

Alder, V. A., Boltovskoy, D. (1991). Microplanktonic distributional patterns west of the Antarctic Peninsula, with special emphasis on the tintinnids. Polar Biol. 11: 103-112

Atkinson, A., Ward, P., Williams, R., Poulet, S. A. (1992). Diel vertical migration and feeding of copepods at an oceanic station near South Georgia. Mar. Biol. 113(4): 583-593

Bakker, C., Phaff, W. J. (1979). The genus Tintinnopsis Stein. Hydrobiologia 50: 101-111

Balech, E. (1958a). Dinoflagellés Tintinnides de la Terre Adelie (Secteur Francais Antarctique). Vie Milieu 8: $382-408$

Balech, E. (1958b). Plancton de la Campaña Antárctica Argentina. Physis, B. Aires 21:75-108

Balech, E. (1973). Segunda contribucion al conocimiento del plancton del Mar de Bellingshausen. Contrnes Inst. antarct. argent. 107: 3-63

Boltovskoy, D., Alder, V. A., Spinelli, F. (1989). Summer Weddell Sea microplankton: assemblage structure, distribution and abundance, with special empahsis on the Tintinnina. Polar Biol. 9: $447-456$

Boltovskoy, D., Dinofrio, E. O., Alder, V. A. (1990). Intraspecific variability in Antarctic tintinnids: the Cymatocylis affinis/ convallaria species group. J. Plankton Res. 12: 403-413

Clarke, K. R. (1993). Non-parametric multivariate analysis of changes in community structure. Aust. J. Ecol. 18: $117-143$

Culverhouse, P. F., Ellis, R. E., Simpson, R. G., Williams, R., Pierce, R. W. Turner, J. T (1994). Automatic categorisation of five species of Cymatocylis (Protozoa, Tintinnida) by artificial neural network. Mar. Ecol. Prog. Ser. 107: $273-280$

Davis, C. C. (1978). Variations of the lorica in the genus Parafavella (Protozoa: Tintinnida) in northern Norway waters. Can. J. Zool. 56: 1822-1827

Davis, C. C. (1981), Variations in the lorica shape in the genus Ptychocylis (Protozoa: Tintinnina) in relation to species identification. J. Plankton Res. 3: 433-443

Garrison, D. L. (1991). An overview of the abundance and role of protozooplankton in Antarctic waters. J. mar. Sys. 2: $317-331$

Gold, K., Morales, E. A. (1975). Seasonal changes in lorica sizes and the species of Tintinnida in the New York Bight. J. Protozool. 22: 520-528

Gold, K., Morales, E. A. (1976). Studies on the sizes, shapes and development of the lorica of agglutinated Tintinnida. Biol. Bull. 150: 377-392

Gonzalez, R. C., Woods, R. E. (1992). Digital image processing. Addison-Wesley, Massachusetts

Laackmann, H. (1907). Antarktische Tintinnen. Zool. Anz. 31 : 235-239

Laval-Peuto, M. (1981). Construction of the lorica in Ciliata, Tintinnina. In vivo study of Favella ehrenbergii: variability of the phenotypes during the cycle, biology, statistics, biometry. Protistologica 17: 249-272

Laval-Peuto, M. (1982). Methods of taxonomy and selection of criteria for determination of marine planktonic protozoa. Annls Inst. océanogr., Paris 58:151-168

Laval-Peuto, M. (1983). Sexual reproduction in Favella ehrenbergii (Ciliophora, Tintinnina). Taxonomical implications. Protistologica 29: 503-512

Laval-Peuto, M., Brownlee, D. C. (1986). Identification and systematics of the Tintinnina (Ciliophora): evaluation and suggestions for improvement. Annls Inst. océanogr., Paris 62: $69-84$ 
Phillips, B. F., Campbell, N. A., Wilson, B. R. (1973). A multivariate study of geographic variation in the whelk Dicathais. J. exp. mar. Biol. Ecol. 11: 27-69

Pierce, R. W., Turner, J. T (1993). Global biogeography of marine tintinnids. Mar. Ecol. Prog. Ser. 94:11-26

SAS Institute (1985). SAS user's guide: statistics, Version 5 edn. SAS Institute Inc., Cary, NC

Sassi, R. Melo, G. D. N. (1986) Tintinnina (ProtozoaCiliophora Oligotrichida) from the First Brazilian Expe-

This article was submitted to the editor dition to the Antarctic. Anais Acad bras. Ciènc 58 $63-84$

Wasik, A., Mikolajczyk, E. (1990). Tintinnuds near pack-ice between South Shetland and the South Orkney Islands (26 Dec. 1988-18 Jan. 1989). Acta protozool., Warsz. 29. $229-244$

Williams, R., Collins, N. R., Conway, D. V. P. (1983). The double LHPR system, a high speed micro- and macroplankton sampler. Deep Sea Res. 30: 331-342

Manuscript first received: September 21, 1993

Revised version accepted: January 18, 1994 